\title{
Parents' Knowledge and Attitudes on Childhood Immunization, Taif, Saudi Arabia
}

Yousif MA, Ahmed Abdulrahman Albarraq, Mustafa Awad A Abdallah and Abubaker Ibrahim Elbur*

Pharmacy Practice Research Unit, College of Pharmacy, Taif University, Kingdom of Saudi Arabia

\begin{abstract}
Background: Parents' knowledge and attitudes towards immunization are likely influence uptake. The objective of this study was to assess parental knowledge, and attitudes on childhood immunization among Saudi parents.

Methods: A cross-sectional survey was conducted during April 2013 in Taif, Saudi Arabia. Convenient method of sampling was adopted. Parents with children of 0-12 years old were invited to participate. Data was collected through face- to -face interview method using a pre-tested structured questionnaire. Data was processed using the software Statistical Package for Social Science (SPPS) (Version 21). Descriptive statistics were used to describe all variables. Association between dependent variables (knowledge, and attitudes) and independent ones (parents' demographics) were tested using Chi-square test. $\mathrm{P}$ values of $<0.05$ were considered statistically significant.

Results: A total of 731 parents were recruited. Parents had good knowledge on aspects related to the general role of vaccination in prevention of some infectious diseases $672(91.9 \%)$, timing of the first dose in vaccination schedule 635(86.9\%). However, poor knowledge was documented among parents in other aspects like the importance of administration of multiple doses of the same vaccine to child immunity $304(41.6 \%)$, administration of multiple vaccines at the same time have no negative impacts on child immunity $271(37.1 \%)$, vaccination of children against seasonal influenza 334(45.7\%) and contraindication to vaccination $287(39.3 \%)$. Parents attitudes towards immunization was positive expect in some aspects related to vaccination side effects $316(34.2 \%)$ and the probability of occurrence of diseases against which the child was vaccinated $288(39.4 \%)$. Gender, residence and educational level were found to be significantly associated with both parents' knowledge and attitudes towards immunization.

Conclusions and recommendations: Although parents had good knowledge and positive attitudes on some aspects related childhood immunization, gaps in both studied domains were identified. Educational interventions are needed to upgrade parents' knowledge with special emphasis on less educated and residents of rural areas.
\end{abstract}

Keywords: Parents; Knowledge; Attitude; Childhood immunization

\section{Introduction}

Immunization has greatly reduced the burden of infectious diseases [1]. Immunization prevents illness, disability and death from vaccine-preventable diseases including diphtheria, measles, pertussis, pneumonia, polio, rotavirus diarrhoea, rubella and tetanus [2].

Parents' knowledge about immunization and their attitudes towards them are likely influence uptake [3]. Previous studies revealed misconceptions on parents' knowledge and negative attitudes towards childhood immunization. Mothers' knowledge about vaccination was found to be quite low and their educational status was significantly associated with child's coverage [4]. Negative attitude, for example mothers fear from vaccination, was found to be significantly affected the immunization status of their children [5]. Zagminas et al. [6] assessed parents' knowledge on immunization and noted that most of the respondents can be characterized as having a positive opinion about vaccination, although $20-40 \%$ of respondents indicated insufficient knowledge on this issue. Greater concern about the safety of vaccines was expressed by older parents, residents of towns and highly educated individuals [7]. On the other hand researchers in developed world found parents' attitudes and beliefs had little effect on their children's immunization levels [8].

Despite the fact that local and systemic reactions to vaccines are identified [9], but they were found to be one of the barriers to childhood immunization among other factors [10].

An increasing number of parents are questioning the safety and necessity of routine childhood immunizations. The belief that vaccines cause autism was the most prevalent parental concern in a survey conducted in USA [11].

Although researches have been published on parents' knowledge, attitudes and practices regarding childhood vaccination no such studies have been reported in Saudi Arabia. Therefore, this study was undertaken to assess parental knowledge, and attitudes on childhood immunization among Saudi parents.

\section{Methods}

A cross-sectional survey was conducted during the period of one month (April 2013) in Taif, Saudi Arabia. Convenient method of sampling was adopted. Parents with children of 0-12 years old were invited to participate. Verbal informed consent was obtained and participation was optional. Data was collected by trained pharmacy students from parents in public places in the town. Some students also recruited some of their eligible relatives. Face- to -face

*Corresponding author: Abubaker Ibrahim Elbur, Pharmacy Practice Research Unit, College of Pharmacy, Taif University P.O. Box: 888, 21974, Al-Haweiah, Taif, Kingdom of Saudi Arabia, Tel: +966541399649; E-mail: bakarelbu@yahoo.co.uk

Received November 17, 2013; Accepted December 24, 2013; Published December 28, 2013

Citation: Yousif MA, Albarraq AA, Abdallah MAA, Elbur Al (2013) Parents' Knowledge and Attitudes on Childhood Immunization, Taif, Saudi Arabia. J Vaccines Vaccin 5: 215. doi: 10.4172/2157-7560.1000215

Copyright: @ 2013 Yousif MA, et al. This is an open-access article distributed under the terms of the Creative Commons Attribution License, which permits unrestricted use, distribution, and reproduction in any medium, provided the original author and source are credited. 
interview method was used and responses were recorded in a pretested structured questionnaire. The questions were formulated based on questions and answers published by the Ministry of Health Saudi Arabia [12]. The questionnaire was thoroughly revised by the research team for validity, comprehensiveness, and appropriateness to collect the required information from the targeted population. The questionnaire was composed of three main sections to collect data on parents' demographics, parents' knowledge and attitudes on childhood immunization. Responses to knowledge questions were recorded as "Yes", "No", and "Don't know". A five point-likert scale ("Strongly agree", "Agree", "Not sure", "Disagree", and "Strongly disagree") was used to assess parents' attitudes toward childhood immunization. The questionnaire was tested with a group of 20 parents. Minor modifications were suggested and adopted in the final questionnaire.

Data was processed using the software Statistical Package for Social Science (SPPS) (Version 21). Descriptive statistics were used to describe all variables. Association between dependent variables (knowledge, and attitudes) and independent ones (parents' demographics) were tested using Chi-square test. $P$ values of $<0.05$ were considered statistically significant.

Ethical approval for the study was obtained from Pharmacy Practice Research Unit (PPRU), College of Pharmacy, Taif University, Taif, Saudi Arabia

\section{Results}

\section{Parents' demographics}

Overall 731 parents were recruited, of them 465 (63.6\%) were females. More than two third of the respondents their ages were < 40 years $\{502(68.7 \%)\}$ and $634(86.7 \%)$ were residing in the town. University graduates were $410(56.1 \%)$. Table 1 shows parents' demographics.

\section{Parental knowledge on childhood immunization}

The majority of parents $672(91.9 \%)$ knew the role of routine vaccination in protecting children from some infectious diseases and its complications. A considerable number of 635 (86.9\%) parents knew the timing of the first dose in vaccination schedule. Five hundred and sixty

\begin{tabular}{|l|c|c|}
\hline Background characteristic & Frequency & Percentage \\
\hline Gender & 266 & 36.4 \\
Male & 465 & 63.6 \\
\hline Female & & \\
\hline Age groups (in year) & 206 & 28.2 \\
18-29 & 296 & 40.5 \\
$30-39$ & 172 & 23.5 \\
$40-49$ & 57 & 7.8 \\
\hline 50 \& above & & \\
\hline Residence & 634 & 86.7 \\
\hline Town & 97 & 13.3 \\
\hline Outside town & 410 & 56.1 \\
\hline Educational level & 219 & 30.0 \\
University & 69 & 9.4 \\
Secondary & 33 & 4.5 \\
\hline Primary & 115 & 15.7 \\
\hline Iliterate & 285 & 39.0 \\
\hline Number of children & 331 & 45.3 \\
\hline One & 731 & 100 \\
\hline 2-3 & & \\
\hline >3 & Table 1: Parents' demographics. \\
\hline Total &
\end{tabular}

Table 1: Parents' demographics. eight parents knew that the incidence of most diseases against which children are vaccinated occur during the first years of life. Less than half of the interviewees $304(41.6 \%)$ knew that administration of multiple doses of the same vaccine is important for child immunity. More than one third of the parents knew that concomitant administration of multiple vaccines have no negative impacts on child immunity. Nearly three quarter of the parents agreed with the importance of vaccinating children during immunization campaigns. Out of the total parents 334 (45.7\%) agreed that it is recommended to vaccinate children against seasonal influenza and $512(70 \%)$ denied that there is association between immunization and autism. Common colds, ear infection, and diarrhea were considered as contraindications for vaccination by $280(38.3 \%)$ of the parents. Table 2 shows parents' knowledge on childhood immunization correlated to their demographics.

\section{Parents' attitude towards childhood immunization}

Parental attitudes towards childhood immunization were shown in Table 3. The majority 719 (98.4\%) of the parents either strongly agreed or agreed that child immunization is important. Most 669 (91.5\%) of them considered immunization is more beneficial than harmful and $534(73 \%)$ strongly agreed or agreed that vaccines are safe. Out of parents $606(82.9 \%)$ and $415(56.8 \%)$ parents strongly agreed or agreed that child immunization is not prohibited in religion and the administration of vaccines is associated with side effects respectively. Nearly forty percent of parents were not sure if the child becomes infected after immunization with the disease/s against which he/she was vaccinated or not. The majority $660(90.3 \%)$ and $680(93 \%)$ of the parents strongly agreed or agreed that compliance to immunization schedule is important and immunization keep the child healthy respectively.

Cross tabulation showed significant associations between parents' educational level and different statements designed to assess their attitudes towards immunization as shown on Table 4.

\section{Discussion}

Analysis of the demographic characteristics of the parents participated in the present study showed that the mothers constituted the majority of the sample. Understanding mothers' knowledge and attitudes towards immunization is important, although the father's involvement was shown to be associated with the child's vaccination status [13]. More than half of the parents had higher education. This may be explained by the fact that the majority of the participants were living in the town where they were originally born and had better chances to complete their higher education.

Assessment of the parents' knowledge in the current study showed variations in responses to questions designed to assess their knowledge on childhood immunization. The majority of them knew that routine vaccination prevent children from some serious infectious diseases and its complication. In contrast, in study conducted in UAE more than $85 \%$ of the participants knew the role of childhood vaccination in prevention of life-threatening diseases [14].

Most vaccines in the childhood immunization schedule require two or more doses for development of an adequate and persisting antibody response [15]. Only $41.6 \%$ of the interviewees correctly knew the importance of administration of multi-doses of the same vaccine given at intervals for child immunity. The consequence of this finding is that parents may think that only the first shot of the vaccine is sufficient to develop immunity and protect their children. 
Citation: Yousif MA, Albarraq AA, Abdallah MAA, Elbur Al (2013) Parents' Knowledge and Attitudes on Childhood Immunization, Taif, Saudi Arabia. J Vaccines Vaccin 5: 215. doi: 10.4172/2157-7560.1000215

Page 3 of 5

\begin{tabular}{|c|c|c|c|c|}
\hline Item & Yes & No & Don't know & Significance and $\boldsymbol{P}$ value \\
\hline $\begin{array}{l}\text { Routine vaccination prevent children from some } \\
\text { infectious diseases and its complications }\end{array}$ & $672(91.9 \%)$ & $16(2.2 \%)$ & $43(5.9 \%)$ & \\
\hline First dose in vaccination given at birth & $635(86.9 \%)$ & $35(4.8 \%)$ & $61(8.3 \%)$ & $\begin{array}{l}\text { Gender }(P=0.017) \text {, age }(P=0.000) \text {, residence }(P=0.000) \text {, } \\
\text { educational level }(P=0.000) \text {, }\end{array}$ \\
\hline $\begin{array}{l}\text { Most diseases against which children are vaccinated } \\
\text { occur during the first years of life }\end{array}$ & $568(77.7 \%)$ & $71(9.7 \%)$ & $92(12.6 \%)$ & Residence $(P=0.048)$, educational level $(P=0.017)$, \\
\hline $\begin{array}{l}\text { Multi-doses of the same vaccine given at intervals are } \\
\text { important for child immunity }\end{array}$ & $304(41.6 \%)$ & $254(34.7 \%)$ & $173(23.7 \%)$ & Gender $(P=0.019)$, educational level $(P=0.004)$ \\
\hline $\begin{array}{l}\text { More than one vaccine at the same time have no } \\
\text { negative impacts on child immunity }\end{array}$ & $271(37.1 \%)$ & $269(36.8 \%)$ & $191(26.1 \%)$ & Gender $(P=0.024)$ \\
\hline $\begin{array}{l}\text { Is it important to vaccinate children during } \\
\text { immunization campaigns }\end{array}$ & $540(73.9 \%)$ & $128(17.5 \%)$ & $63(8.6 \%)$ & \\
\hline $\begin{array}{l}\text { It is recommended to vaccinate children against } \\
\text { seasonal influenza }\end{array}$ & $334(45.7 \%)$ & $183(25 \%)$ & $214(29.3 \%)$ & $\begin{array}{l}\text { Age }(P=0.016) \text {, residence }(P=0.005) \text {, educational level } \\
(P=0.011)\end{array}$ \\
\hline Immunization can cause autism & $61(8.3 \%)$ & $512(70 \%)$ & $158(21.6 \%)$ & $\begin{array}{l}\text { Age }(P=0.009) \text {, residence }(P=0.001) \text {, educational level } \\
(P=0.013) \text {. }\end{array}$ \\
\hline $\begin{array}{l}\text { Common colds, ear infection, and diarrhea are not } \\
\text { contraindications for vaccination }\end{array}$ & $280(38.3 \%)$ & $287(39.3 \%)$ & $164(22.4 \%)$ & Gender $(P=0.000)$ \\
\hline
\end{tabular}

Table 2: Knowledge on childhood immunization correlated to parents' demographics.

\begin{tabular}{|c|c|c|c|c|c|}
\hline item & Strongly agree & Agree & Not sure & Disagree & Strongly disagree \\
\hline Child immunization is important & $619(84.7 \%)$ & $100(13.7 \%)$ & $9(1.2 \%)$ & $1(0.1 \%)$ & $2(0.3 \%)$ \\
\hline Immunization is more beneficial than harmful & $427(58.4 \%)$ & $242(33.1 \%)$ & $47(6.4 \%)$ & $14(1.9 \%)$ & $1(0.1 \%)$ \\
\hline Vaccines for child immunization are safe & $280(38.3 \%)$ & $254(34.7 \%)$ & $158(21.6 \%)$ & $31(4.2 \%)$ & $8(1.1 \%)$ \\
\hline Child immunization is prohibited in religion & $18(2.5 \%)$ & $20(2.7 \%)$ & $87(11.9 \%)$ & $225(30.8 \%)$ & $381(52.1 \%)$ \\
\hline Immunization associated with side effects & $117(16 \%)$ & $298(40.8 \%)$ & $213(29.1 \%)$ & $73(10 \%)$ & $30(4.1 \%)$ \\
\hline $\begin{array}{l}\text { Child can become infected after immunization with the disease/s against which } \\
\text { he/she was vaccinated }\end{array}$ & $63(8.6 \%)$ & $144(19.7 \%)$ & $288(39.4 \%)$ & $170(23.3 \%)$ & $66(9.0 \%)$ \\
\hline Compliance to immunization schedule is important & $473(64.7 \%)$ & $187(25.6 \%)$ & $48(6.6 \%)$ & $18(2.5 \%)$ & $5(0.7 \%)$ \\
\hline Immunization keep your child healthy & $462(63.2 \%)$ & $218(29.8 \%)$ & $38(5.2 \%)$ & $6(0.8 \%)$ & $7(1.0 \%)$ \\
\hline
\end{tabular}

Table 3: Parents' attitudes towards childhood immunization.

\begin{tabular}{|c|c|c|c|c|c|c|c|}
\hline \multicolumn{8}{|c|}{ Child immunization is important } \\
\hline Education level & Strongly agree & Agree & Not sure & Disagree & Strongly disagree & Total & $P$ value \\
\hline University & $86.3 \%$ & $12.7 \%$ & $0.7 \%$ & $0.0 \%$ & $0.2 \%$ & 410 & \multirow{4}{*}{0.002} \\
\hline Secondary & $84.5 \%$ & $14.2 \%$ & $1.4 \%$ & $0.0 \%$ & $0.0 \%$ & 219 & \\
\hline Primary & $79.7 \%$ & $15.9 \%$ & $2.9 \%$ & $0.0 \%$ & $1.4 \%$ & 69 & \\
\hline Illiterate & $75.8 \%$ & $18.2 \%$ & $3 \%$ & $3 \%$ & $0.0 \%$ & 33 & \\
\hline \multicolumn{7}{|c|}{ Immunization is more beneficial than harmful } & \multirow{5}{*}{0.007} \\
\hline University & $65.4 \%$ & $29.3 \%$ & $4.1 \%$ & $1.2 \%$ & $0.0 \%$ & 410 & \\
\hline Secondary & $50.7 \%$ & $38.4 \%$ & $7.8 \%$ & $2.7 \%$ & $0.5 \%$ & 219 & \\
\hline Primary & $47.8 \%$ & $36.2 \%$ & $13.0 \%$ & $2.9 \%$ & $0.0 \%$ & 69 & \\
\hline Illiterate & $45.5 \%$ & $39.4 \%$ & $12.1 \%$ & $3.0 \%$ & $0.0 \%$ & 33 & \\
\hline \multicolumn{8}{|c|}{ Child immunization is prohibited in religion } \\
\hline University & $1.7 \%$ & $2.9 \%$ & $9.5 \%$ & $28.8 \%$ & $57.1 \%$ & 410 & \multirow{4}{*}{0.044} \\
\hline Secondary & $2.7 \%$ & $3.2 \%$ & $14.6 \%$ & $31.5 \%$ & $47.9 \%$ & 219 & \\
\hline Primary & $2.9 \%$ & $0.0 \%$ & $14.5 \%$ & $37.7 \%$ & $44.9 \%$ & 69 & \\
\hline Illiterate & $9.1 \%$ & $3.0 \%$ & $18.2 \%$ & $36.4 \%$ & $33.3 \%$ & 33 & \\
\hline \multicolumn{8}{|c|}{ Child can become infected after immunization with the disease/s against which he/she was vaccinated } \\
\hline University & $7.3 \%$ & $23.2 \%$ & $35.4 \%$ & $23.4 \%$ & $10.7 \%$ & 410 & \multirow{4}{*}{0.015} \\
\hline Secondary & $7.8 \%$ & $17.4 \%$ & $42.9 \%$ & $24.2 \%$ & $7.8 \%$ & 219 & \\
\hline Primary & $13.0 \%$ & $10.1 \%$ & $49.3 \%$ & $23.2 \%$ & $4.3 \%$ & 69 & \\
\hline Illiterate & $21.2 \%$ & $12.1 \%$ & $45.5 \%$ & $15.2 \%$ & $6.1 \%$ & 33 & \\
\hline \multicolumn{8}{|c|}{ Compliance to immunization schedule is important } \\
\hline University & $67.8 \%$ & $24.4 \%$ & $5.4 \%$ & $2.0 \%$ & $0.5 \%$ & 410 & \multirow{4}{*}{0.003} \\
\hline Secondary & $63.0 \%$ & $28.3 \%$ & $5.9 \%$ & $2.7 \%$ & $0.0 \%$ & 219 & \\
\hline Primary & $58.0 \%$ & $24.6 \%$ & $10.1 \%$ & $2.9 \%$ & $4.3 \%$ & 69 & \\
\hline Illiterate & $51.5 \%$ & $24.2 \%$ & $18.2 \%$ & $6.1 \%$ & $0.0 \%$ & 33 & \\
\hline \multicolumn{8}{|c|}{ Immunization keep your child healthy } \\
\hline University & $66.3 \%$ & $27.8 \%$ & $4.4 \%$ & $0.7 \%$ & $0.7 \%$ & 410 & \multirow{4}{*}{0.011} \\
\hline Secondary & $62.6 \%$ & $31.5 \%$ & $5.0 \%$ & $0.5 \%$ & $0.5 \%$ & 219 & \\
\hline Primary & $52.2 \%$ & $37.7 \%$ & $5.8 \%$ & $2.9 \%$ & $1.4 \%$ & 69 & \\
\hline Illiterate & $51.5 \%$ & $27.3 \%$ & $15.2 \%$ & $0.0 \%$ & $6.1 \%$ & 33 & \\
\hline
\end{tabular}

Table 4: Association between attitudes on childhood immunization and parents' educational level. 
To date there is no scientific evidence that supports parents' fears about combined vaccines causing immune overload [16]. Only $37.1 \%$ of the participants knew that the administration of more than one vaccine at the same time have no negative impacts on child immunity. In contrast, in another study quarter of the parents believed that their child's immune system could become weakened as a result of too many immunizations [17].

During mass immunization a large number of children can be reached who for a variety of reasons never get immunized through routine immunization or are unable to complete the recommended immunization schedule. In the current study (73.9\%) of the parents agreed with the importance vaccinating children during immunization campaigns. In Uganda parents/caretakers perceived vaccines used during mass immunization not to be safe either because they are expired or are deliberately contaminated with harmful agents intended to harm their children [18].

Current recommendation in USA is to vaccinate all children from 6 months up to 19 years - with particular emphasis on children under the age of 5 year or with chronic illnesses with Influenza vaccines [19]. Nearly $45 \%$ of the parents knew that vaccination of children against seasonal influenza is important. Parents might be motivated to vaccinate their children if educated about the central role of children in transmitting the infection in households and communities, beside the health and economic burden of contracting influenza [20].

Parents need reliable and accurate information on true contraindications to vaccination. Out of the participated parent $61.7 \%$ considered or did not know that common colds, ear infection, and diarrhea are not contraindications for vaccination. Delay of immunization based on misconceptions about contra- indications puts an infant or child at risk [21].

Generally the results of present survey revealed that parents had positive attitudes on childhood immunization with regard the majority of investigated items. Similar findings were reported in other studies in different parts of the world [14,22-24].

Generally the administration of vaccines may be associated with common local reactions like pain, swelling, and redness at the injection site [9]. Systemic reactions, including fever, irritability, drowsiness, and rash, may also occur. More than half of the recruited parents strongly agreed or agreed that immunization associated with side effects. In another survey nearly $20 \%$ of the interviewed parents considered administration of vaccines is associated with undesirable effect like allergies and asthma. Parents should be educated about these side effects. Nnenna et al. [25] found that one-fifth of the recruited mothers would not continue immunization should their own child suffer any adverse reaction.

The results of the present survey revealed significant association between parents' educational level and knowledge and attitudes on childhood immunization. Higher educational level, of no doubt, helps the parents to understand the educational messages. Moreover, such parents have better chances to come across considerable knowledge about immunization in the media, this finding coincide with the results of other studies $[24,26]$. Significant variations between mothers and fathers in knowledge had been observed in the current study. Mothers almost in all cases used to accompany their children to immunization visits. Communication with healthcare providers may be responsible for the observed difference in mothers' knowledge compared to fathers' awareness. Significant differences were documented in knowledge and attitudes of parents who were living in the city compared to those who were residing outside the town. This may be explained by the difference in educational level or may be due to variation in the provided health services.

\section{Study limitation}

This survey was conducted in small geographical area in Saudi Arabia; therefore the obtained results cannot be generalized to the parents in all the country. Future researches on the topic need recruitment of parents from different areas in the country.

\section{Conclusions and Recommendations}

In conclusion the results of the present survey showed that parents had good knowledge and positive attitudes on some aspects related childhood immunization. However, gaps in both studied domains were identified. Educational interventions are needed to upgrade parents' knowledge with special emphasis on less educated and residents of rural areas.

\section{Acknowledgement}

The authors would like to appreciate the great effort done in data collection by Second Year Students, College of pharmacy, Taif University.

\section{References}

1. Andre FE, Booy R, Bock HL, Clemens J, Datta SK, et al. (2008) Vaccination greatly reduces disease, disability, death and inequity worldwide. Bull World Health Organ 86: 140-146.

2. World Health organization media centre (2013) Immunization coverage Fact sheet N`378 April 2013.

3. Jheeta M, Newell J (2008) Childhood vaccination in Africa and Asia: the effects of parents' knowledge and attitudes. Bull World Health Organ 86: 419.

4. Siddiqi N, Siddiqi AE, Nisar N, Khan A (2010) Mothers' knowledge about EPI and its relation with age-appropriate vaccination of infants in peri-urban Karachi. J Pak Med Assoc 60: 940-944.

5. Kimmel SR, Burns IT, Wolfe RM, Zimmerman RK (2007) Addressing immunization barriers, benefits, and risks. J Fam Pract 56: S61-69.

6. Zagminas K, Surkiene G, Urbanovic N, Stukas R (2007) [Parental attitudes towards children's vaccination]. Medicina (Kaunas) 43: 161-169.

7. Rogalska J, Augustynowicz E, Gzyl A, Stefanoff P (2010) [Parental attitudes towards childhood immunisations in Poland]. Przegl Epidemiol 64: 91-97.

8. Strobino D, Keane V, Holt E, Hughart N, Guyer B (1996) Parental attitudes do not explain underimmunization. Pediatrics 98: 1076-1083.

9. Kimmel SR (2002) Vaccine adverse events: separating myth from reality. Am Fam Physician 66: 2113-2120.

10. Thomas M, Kohli V, King D (2004) Barriers to childhood immunization: findings from a needs assessment study. Home Health Care Serv Q 23: 19-39.

11. Smith MJ, Woods CR, Marshall GS (2009) Parental vaccine concerns in Kentucky. J Ky Med Assoc 107: 342-349.

12. http://www.moh.gov.sa/HealthAwareness/EducationalContent/vaccination/ Pages/Questions.aspx

13. Mapatano MA, Kayembe K, Piripiri L, Nyandwe K(2008) Immunisation-related knowledge, attitudes and practices of mothers in Kinshasa, Democratic Republic of the Congo. SA Fam Pract. 50: 61-61e.

14. Bernsen RM, Al-Zahmi FR, Al-Ali NA, Hamoudi RO, Ali NA, et al. (2011) Knowledge, attitude and practice towards immunizations among mothers in a traditional city in the United Arab Emirates. Journal of Medical Sciences. 4: 114-121.

15. Centre for Disease Control and Prevention (2011) General Recommendations on Immunization.

16. Hilton S, Petticrew M, Hunt K (2006) 'Combined vaccines are like a sudden 
Citation: Yousif MA, Albarraq AA, Abdallah MAA, Elbur Al (2013) Parents' Knowledge and Attitudes on Childhood Immunization, Taif, Saudi Arabia. J Vaccines Vaccin 5: 215. doi: 10.4172/2157-7560.1000215

onslaught to the body's immune system': parental concerns about vaccine 'overload' and 'immune-vulnerability'. Vaccine 24: 4321-4327.

17. Gellin BG, Maibach EW, Marcuse EK (2000) Do parents understand immunizations? A national telephone survey. Pediatrics 106: 1097-1102.

18. Asiimwe D, Kibombo R, Matsiko J (2006) Vaccine safety perceptions among parents in developing countries and influence of adverse events following immunization (AEFI) on their decisions to vaccinate children.

19. Center for Disease Control and Prevention. Children, the flu and flu vaccine.

20. Principi N, Esposito S (2004) Pediatric influenza prevention and control. Emerg Infect Dis 10: $574-580$.

21. [No authors listed] (2000) A guide to contraindications to childhood vaccinations. Can J Infect Dis 11: 13-14.

22. Asim M, Malik N, Yousaf H, Gillani I, Habib N (2012) An Assessment of parental knowledge, belief and attitude toward childhood immunization among mnorities in rural areas of District Faisalabad, Pakistan. Mediterranean Journal of Socia Sciences 3: 153-159.

23. Mollema L, Wijers N, Hahné SJ, van der Klis FR, Boshuizen HC, et al. (2012) Participation in and attitude towards the national immunization program in the Netherlands: data from population-based questionnaires. BMC Public Health 12: 57.

24. Borràs E, Domínguez A, Fuentes M, Batalla J, Cardeñosa N, et al. (2009) Parental knowledge of paediatric vaccination. BMC Public Health 9: 154.

25. Nnenna TB, Davidson UN, Babatunde OI (2013) Mothers' Knowledge and Perception of Adverse Events Following Immunization in Enugu, South-East Nigeria. J Vaccines Vaccin 4: 202.

26. Papazoglou A, Giamaiou K, Poulopoulou S, Pavlopoulou I, Tsoumakas K (2013) The National Vaccination Programme in Greece: Factors Affecting Parents' Knowledge. Global Journal of Medical Research Interdisciplinary. 13. 